\title{
Information Security as Interdisciplinary Science Based on Ethics
}

\author{
Shigeo Tsujii \\ Institute of Information Security, Japan \\ tsujii@isec.ac.jp
}

\begin{abstract}
In my definition, the concept of information security is "the dynamic process for establishing an integrated social infrastructure without infringing freedom broadened by information technology and with closer coordination among technologies, administration and management skills, legal and social systems and information morals in order to simultaneously attain efficiency, enhanced security, protected privacy and minimized surveillance over people." I will discuss the paradigm of information security as an interdisciplinary comprehensive science based on information ethics and the way to develop human resources, showing an example of Institute of Information Security where I serve as the president.
\end{abstract}

